\title{
The Mechanism of Basaltic Explosions: Experimental Modeling
}

\author{
A. Yu. Ozerov \\ Institute of Volcanology and Seismology, Far East Division, \\ Russian Academy of Sciences, Petropavlovsk-Kamchatskii,683006 Russia \\ Received December 14, 2009
}

\begin{abstract}
An instrument package for simulating basaltic eruptions (IPSBE) with a height of $18 \mathrm{~m}$ has been developed for investigating the processes that occur during Strombolian eruptions. The device follows the geometrical ratio between the actual plumbing system of a volcano, with the ratio of conduit diameter to conduit height being 1 to 1000 . For the first time in physical modeling studies, we created conditions in which a moving gas-saturated model liquid enters the conduit; this enabled us to study bubble nucleation, expansion, and coalescence, the generation and transformation of gas structures, and the kinetic features shown by the evolution of the gas phase. These experiments revealed a novel (previously unknown) flow pattern of twophase mixtures in a vertical column, viz., a cluster flow that involves the regular alternation of compact clusters of gas bubbles that are separated by a fluid that does not involve a free gas phase. It is shown that the liquid, bubble, cluster, and slug flow patterns are mutually transformed under certain conditions; they are polymorphous modifications of a gas-saturated liquid moving in a vertical pipe. The data thus acquired suggested a new model for the gas-liquid movement of a magma melt in a conduit: depending on the type of gas-liquid flow behavior at the vent, the crater will exhibit different types of explosive activity, including actual explosions.
\end{abstract}

DOI: $10.1134 / \mathrm{S} 0742046310050015$

The object of study is the Strombolian type of volcanic activity, which is the most frequent type at basaltic volcanoes $[5,16]$.

A Strombolian explosion is a powerful, sudden, and generally unexpected, event. The explosions occur during summit, parasitic, and lateral eruptions. Incandescent volcanic bombs are hurled to heights of hundreds, and more rarely, thousands of meters in the shape of a fan or a vertical plume (Fig. 1a) and afterwards are transported by wind for tens of kilometers. These explosions are usually short-lived; the duration of the active phase is a few seconds or a few tens of seconds. This is followed by a quiet period of a few minutes, tens of minutes, or even hours, with a subsequent explosion again, and so on (Fig. 1b). Such discrete explosions can occur at volcanoes during a few weeks or months, many years, and occasionally hundreds of years. Explosive activity may or may not be accompanied by simultaneous discharge of lava flows. Moderate explosions discharge 30-50 t of solid magmatic ejecta; for more violent events the figures may be as large as 250-1000 t (see Fig. 1a). Strombolian explosions frequently generate shock waves.

Since there is no unambiguous explanation of Strombolian explosions and the diversity they show, we conducted a series of experimental studies in order to throw light on the mechanism of Strombolian activity. Laboratory experiments with two-phase mixtures were started in 2002 and nine gas-liquid experimental devices were designed over 5 years. The result was an instrument package for simulating basaltic eruptions (IPSBE), which was used in a series of experiments. The instrument package used the actual ratios between the parameters of real magmatic plumbing systems, as applied to Klyuchevskoi Volcano.

The goal of this research was to reveal the causes of discrete behavior for eruptions of basaltic magmas. The leading method was experimental investigation of two-phase mixture kinetics in vertical tubes (from the time the first gas bubbles appear until the formation of mature persistent gas structures) in order to compare this behavior with actual volcanic events. An experimental tube was used to simulate the processes that occur in a magma conduit, while the top opening of the tube helped simulate the eruptive effects at the volcano's vent.

We studied changes in the model liquid structure in these experiments as the gas-saturated liquid moved along the vertical column. We describe four gas-liquid flow patterns that occurred in succession, viz., the fluid, bubble, cluster, and slug patterns. Special attention was paid to a previously unknown pattern between the bubble and the slug flow patterns. This new, morphologically persistent gas-liquid flow is the cluster flow pattern. We describe the mechanism that produces the clusters.

The experiments included continuous recording of the acoustic signal at the top of the tube where the model liquid comes to the surface. The acoustic record of the slug flow pattern was compared with the seismogram of an actual signal produced during an eruption of Klyuchevskoi.

The data on the energies of large discrete volcanic explosions, the viscosity of basaltic magmas, and the results of our experimental studies were used to describe 

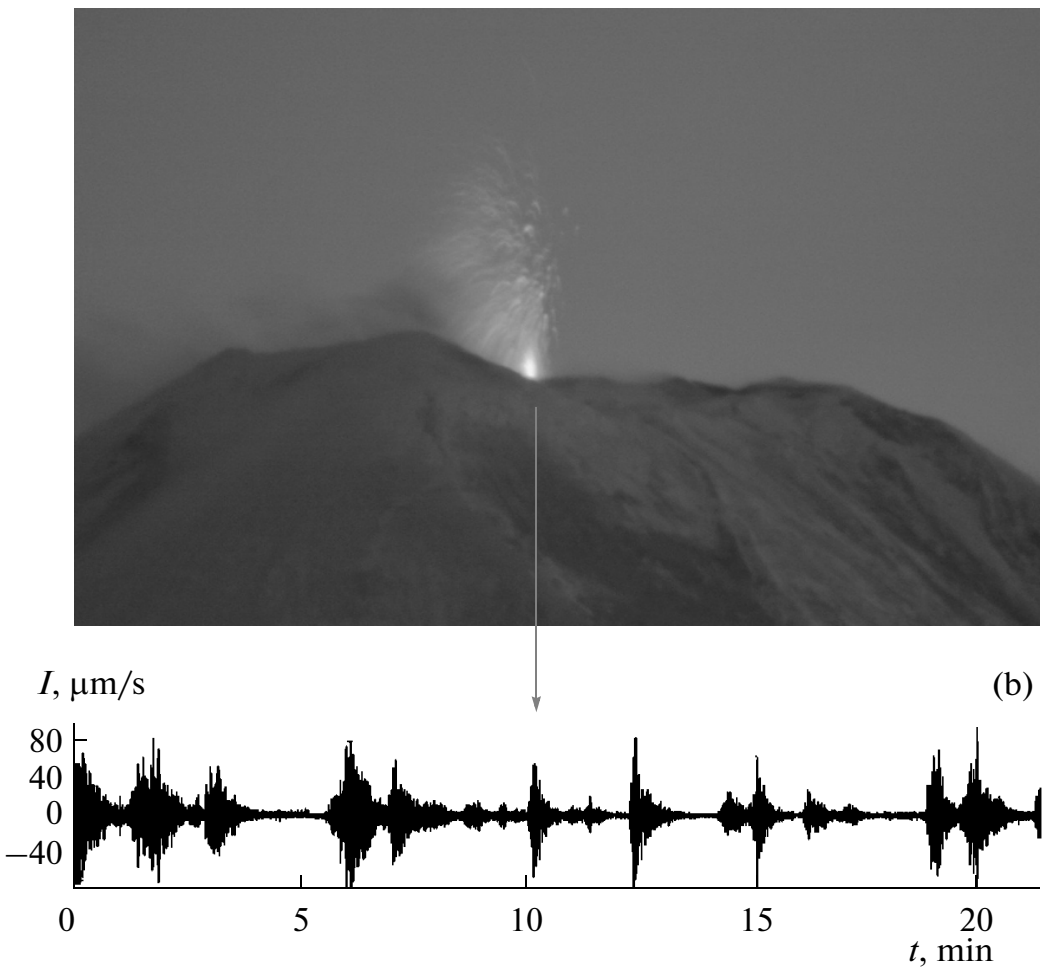

(b)

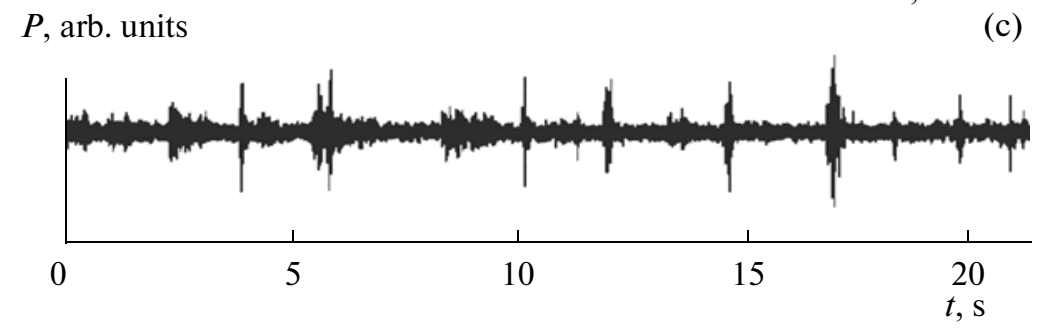

Fig. 1. Comparing the explosive activity on Klyuchevskoi Volcano with the effects of the slug flow at the surface as shown by the IPSBE experimental studies: (a) explosion in the summit crater of Klyuchevskoi Volcano on March 23,2007 (08 h 14 min $30 \mathrm{~s}$ GMT). View from the north. The greatest height of bombs ejected from the crater was $230 \mathrm{~m}$. The volume of ejected magmatic material was $\sim 500 \mathrm{t}$ (lowest estimate). The photograph was taken by Yu.V. Demyanchuk from a distance of $32 \mathrm{~km}$; (b) fragment of a seismic record showing the explosive activity at the Klyuchevskoi summit crater on March 23, 2007 (the record began at $08 \mathrm{~h}$ $04 \mathrm{~min} 30 \mathrm{~s}$ GMT); the horizontal axis shows time $t$ in minutes, the vertical ground motion velocity $I \mu \mathrm{m} / \mathrm{s}$. The record was made at the Loginov seismic station $12 \mathrm{~km}$ from the crater. The data were supplied by the Kamchatka Branch of the RAS Geophysical Service. The arrow marks a seismic event that accompanied the explosion; (c) fragment of an acoustic record showing splashes produced by a slug flow of the model liquid at the top of the IPSBE experimental column; the horizontal axis is time, $s$, the vertical sound wave pressure $P$ in arbitrary units. The recording microphone was $20 \mathrm{~cm}$ from the top of the hose.

possible scenarios that occur in explosions of basaltic magmas. We present a classification for the types of volcanic activity in relation to the type of the gas-liquid flow pattern.

\section{A REVIEW OF THE LITERATURE}

At the end of the 20th century, volcanology arrived at a general approach to the understanding of processes that occur in the top of the plumbing system of a basaltic volcano. Researchers used laws that were available in the hydrodynamics of two-phase gas-liquid systems that occur in vertical tubes and described five flow patterns of two-phase mixtures, viz., bubble, slug, foamy, dispersed, and disperse patterns [11]. A later publication contained a map of gas-liquid flow patterns in vertical tubes [24]. The results of fundamental studies in the flow patterns of two-phase mixtures can be found in review monographs $[14,55]$.

A series of studies was published during the 1960s that purported to explain natural processes (basaltic explosions) in hydrodynamic terms. One of the first researchers of this issue was A. Rittmann [49]; he discussed the possibility of clustered schlieren bubbles rising in a magma column. The first researcher to carry out a straightforward comparison between two-phase mixture flow patterns and 
(a)

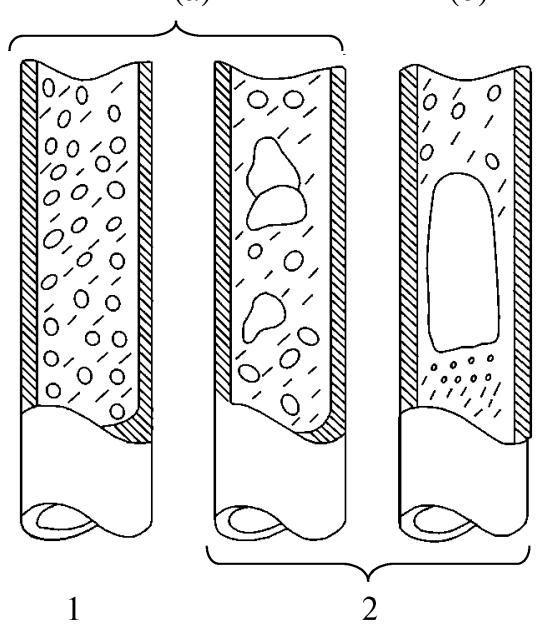

(c)

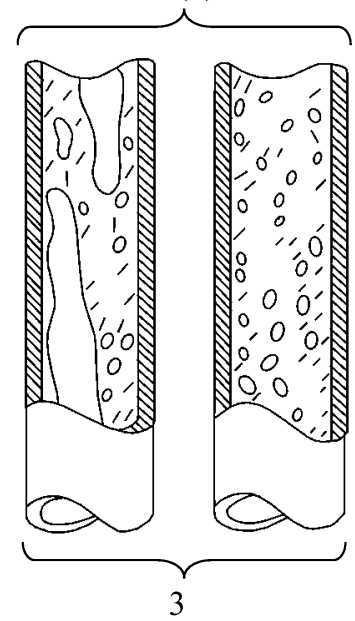

(d)

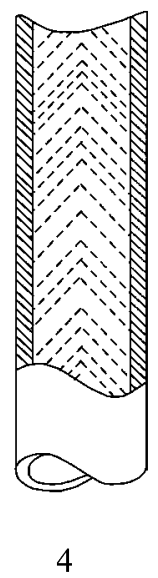

Fig. 2. Correspondence between the flow patterns of two-phase mixtures and eruption types [10]: (a-d) flow patterns in twophase mixtures: (a) bubble, (b) slug, (c) dispersed, (d) disperse. (1-4) eruption types: (1) Hawaiian, (2) Strombolian, (3) EtneanVesuvian, (4) Vulcanian.

the types of volcanic eruption was V.A. Droznin [9]; he continued his research [10] and illustrated it graphically (Fig. 2). These constructions, with some slight modifications, are present in all volcanological publications that treat eruption mechanisms [36, 39, 48, 54]. A review and analysis of the works devoted to applications of hydrodynamic laws to natural processes can be found in [50].

From the above discussion it follows that the outward manifestations of basaltic eruptions are generally described well enough by the concepts of hydrodynamics concerning the movement of two-phase mixtures in vertical tubes. However, the transition from the bubble pattern to the slug pattern remains unresolved. It is known that decreasing pressure in a gas-saturated liquid forces the gas to be released from a dissolved state to the free phase; that is, the nucleation and formation of bubbles take place. It is also known that each individual large bubble in the slug flow pattern produces an "explosion-like" splash at the surface. However, it is not clear why bubbles should coalesce to form large gas structures. For bubbles to coalesce, considerable work is required to make them approach each other and compress. What is the nature of these coalescing forces? Volcanologists have not been able to answer these questions using the results of gas-hydrodynamic research.

Experimental work was done along three lines to attack these problems. The first is an experimental search for novel effects in gas-liquid interactions; afterwards, if such effects were detected, the phenomena in question were to be taken into account when developing the concept of volcanic plumbing systems. The second line of research is simulation of structural changes in a two-phase flow when it passes from a wide "magma chamber" into a narrow "conduit." The third line consists in studying the evolution of two-phase flows in a long thin vertical tube (the "conduit").
The first line of experimental research is treated in [42, 43]. Novel effects were identified in the gas-liquid system. It was shown that freely rising bubbles can coalesce, and foamy structures can undergo stratification in a liquid at rest. In spite of the notable elegance of these studies, it should be stressed that the experiments that served as the basis for subsequent theory were conducted under ideal conditions: (1) in a liquid at rest, (2) through short vertical intervals, and (3) without taking marginal (near-wall) effects into account. The data thus obtained have proved to be insufficient for developing a unified theory of the evolution of a highly moveable two-phase flow that simulates a magma melt rising to the surface.

The second line of research was followed by S. Vergniolle and C. Jaupart $[52,53]$. These researchers put forward an interdisciplinary theory of discrete explosion/spouting, i.e., a synthesis of structural volcanology with gas and fluid dynamics. Their model, which explains the causes of discrete explosions/spouting, is based on the presence of a large intermediate chamber connected to the surface by a thin conduit; the chamber diameter is greater than the conduit diameter by factors of a few hundreds or thousands. A flow of gas bubbles that rises through a liquid meets an obstacle, viz., the roof of a magma chamber; the bubbles are accumulated under the roof, are transformed into foam, and then enter the conduit in discrete portions. This appearance of gas bubbles in the vent in discrete portions leads to a volcanic explosion or a spouting episode. Vergniolle and Jaupart thus require an obligatory structural barrier (the roof of the intermediate chamber), which acts as a storage device and as a proportioner of the gas phase. Many researchers have used the volcanological model of Vergniolle and Jaupart in attempts to explain the discrete arrival of material during volcanic eruptions [36, 37, 38, 48]. 
However, the Vergniolle-Jaupart model is not appropriate for Klyuchevskoi, which is a typical basaltic volcano, which also has been studied in great detail. In the first place, its plumbing system does not contain a shallow magma chamber derivable from seismological and petrologic data $[3,4,6,7,8,19,20,26,27,28,31,33,40,45$, 51]. Secondly, the eruptive activity of Klyuchevskoi shows several sets of clearly identified, persistent periodicities that differ from one another considerably: $\mathrm{T}_{1}=1 \min 34 \mathrm{~s}$, $\mathrm{T}_{2}=6 \mathrm{~min} 10 \mathrm{~s}, \mathrm{~T}_{3}=40 \mathrm{~min}, \mathrm{~T}_{4}=5 \mathrm{~h} 30 \mathrm{~min}$, and $\mathrm{T}_{5}=$ $36 \mathrm{~h}[13,46,44,47]$. If the Vergniolle-Jaupart model is to be used, then one should assume the existence of several magma chambers on the basis of these periodicities; the chambers have to be of different sizes. Moreover, each chamber must have a conduit of its own directly connected to the summit vent. It seems impossible to explain these contradictions in the framework of known gashydrodynamic constructions and simulation studies by Vergniolle and Jaupart.

The present author prefers the third line of research, viz., the study of gas-hydrodynamic effects that arise in long vertical tubes. A special experimental laboratory apparatus (IPSBE) was designed for physical simulation of the eruptive process [18]. This apparatus was used for multidisciplinary simulation of the effects that arise in a vertical tube during the movement of a gas-saturated liquid rather than for fragmentary study of some individual two-phase mixture flow patterns, as was done in previous work. In addition, we studied the effects of each individual flow pattern at the top of the tube. The modeling in the tube was concerned with the processes that occur in the magma conduit, while the top was used to simulate the eruptive effects in the crater (vent) of the volcano.

\section{THE APPARATUS FOR THE SIMULATION OF BASALTIC ERUPTIONS}

When designing this apparatus we tried to incorporate the ratios between the parameters of actual magmatic plumbing systems, mostly as observed at Klyuchevskoi Volcano. We examined the literature relating to Klyuchevskoi to select the most characteristic parameters of its plumbing system. As well, we strove to avoid setting up any structural and energy barriers that could affect the movement of material. Below, we list the leading postulates that this author followed when designing the apparatus (postulates 1 through 10) and for experimental studies (postulates 11-14): (1) uniform supply of magma melt to the plumbing system (conduit) occurs; (2) the magma melt that enters the bottom of the conduit is homogeneous, with no viscosity changes; (3) the conduit cross section is circular or oval; (4) the conduit walls are elastic and thus do not produce any vibrations that could cause sudden changes in melt movement; (5) the height of the conduit is greater than its diameter by factors of a few hundreds or thousands; (6) magma ascends vertically upward along the column; the flow is distinctly laminar in the lower portion of the flow; (7) the melt that enters the bottom of the conduit does not contain a free gas phase; (8) as the melt rises along the conduit, the decreasing pressure gives rise to bubble nucleation with subsequent bubble expansion; (9) the viscosity of the melt is such that gas bubbles move significantly faster compared with the liquid phase; (10) the upper portion of the conduit does not contain any locks consisting of solidified magmatic material that could affect the behavior of the two-phase flow as it comes to the surface (the system is open); (11) the single-phase twocomponent model liquid (water with dissolved carbon dioxide) evolves to become a two-phase two-component system $\left(\mathrm{H}_{2} \mathrm{O}-\mathrm{CO}_{2}\right)$. This feature makes our experiments significantly different from previous work with singlecomponent systems where the liquid and the gas were different physical states of one and the same chemical compound (e.g., water-steam); (12) in these experiments we deliberately neglected a third component, the crystalline phase, which is usually present in magma melts, since its percentage in basaltic melts is insignificant (as well, it seemed to be premature to attack the problem of more complex systems before studying the entire gamut of interactions in the gas-liquid system); (13) the simulation was carried out for an eruption during the mature phase in a ready-made magma conduit and effects related to the precursory period and termination of eruptions were not considered; (14) the experiments were conducted with a model liquid of low gas saturation (pressure below $2 \mathrm{~atm}$ ) at a temperature of $\sim 20^{\circ} \mathrm{C}$; the production of flow patterns with considerable gas discharges (annular, dispersed and disperse) was not envisaged.

The IPSBE was mounted at the Institute of Volcanology and Seismology of the Far East Division of the Russian Academy of Sciences (IVS FED RAS); its total height is $18 \mathrm{~m}$. The apparatus consists of two systems, viz., a modeling system and a recording system. The idea, theory, and the manufacture of all units and the mounting of the IPSBE were carried out by a team of workers at the IVS. The head of the operation was leading researcher A.Yu. Ozerov, engineers A.V. Butkach, V.S. Shul'ga, O.I. D'yachkova, Turner, and milling-machine operator S.F. Laktionov; advice and consultations were rendered by leading researcher V.A. Droznin.

The IPSBE was manufactured for the purpose of studying volcanic processes. Therefore, for the convenience of subsequent discussion of experimental studies the components of the modeling system are made to imitate terms that are relevant to a volcanic system.

The modeling system includes a container for producing a gas-saturated model liquid (magma chamber), a transparent hose (conduit), and an aquarium for reception of the incoming model liquid (crater/vent) (Figs. 3a, $3 b)$. The magmatic system is described in the sequence from the bottom upward.

The "chamber." An experimental analogue of a magma chamber was designed, from which a single-phase liquid containing a dissolved gas comes to the conduit. The "chamber" is a stainless-steel thick-walled sealed tank $2.3 \mathrm{~m}$ high and $3501 \mathrm{in}$ volume. The tank is designed 
(a)

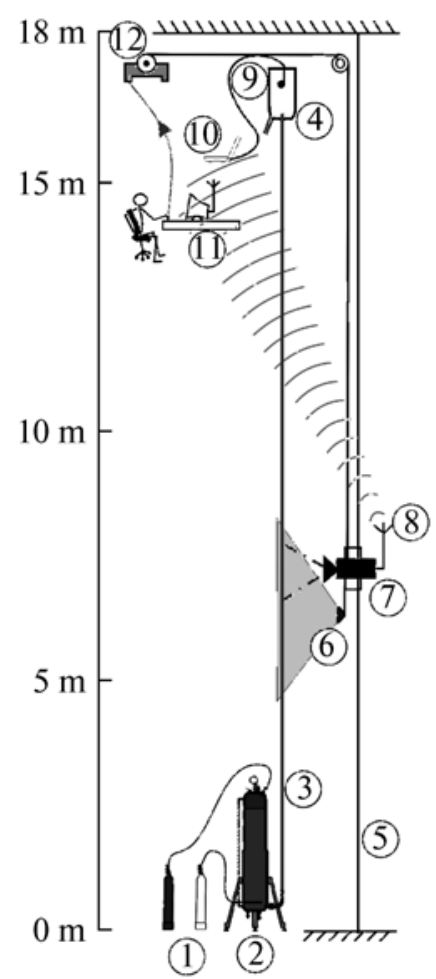

(b)

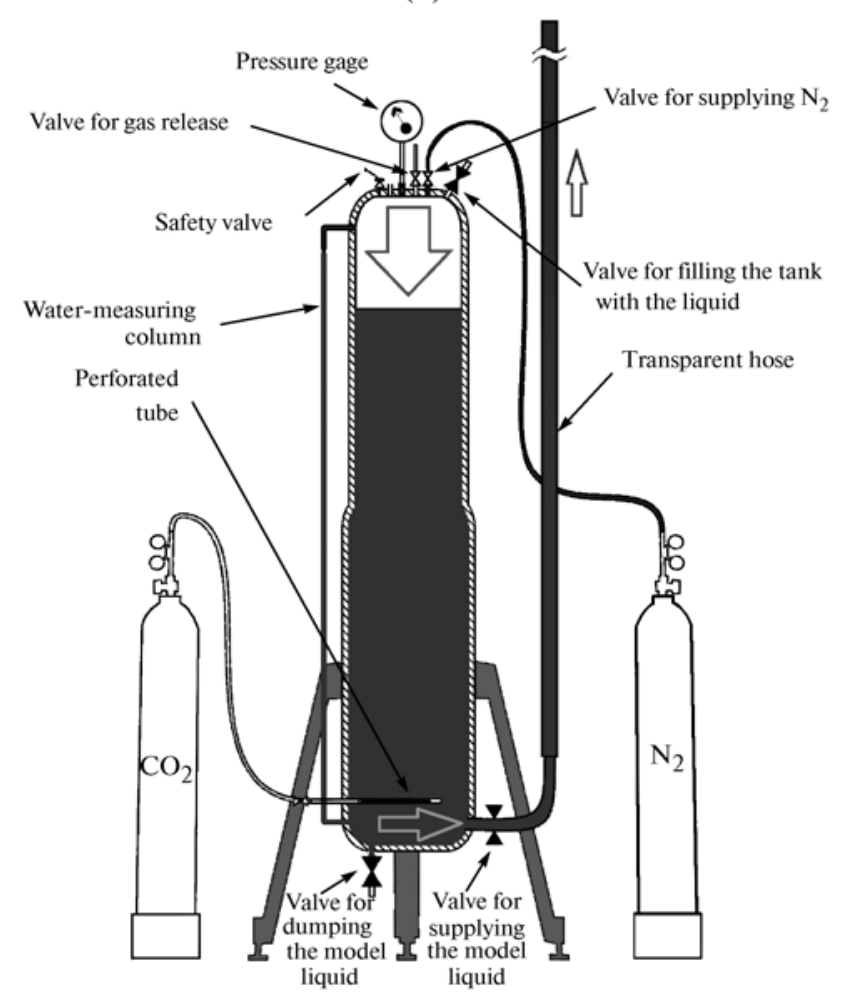

Fig. 3. Instrument package for simulating basaltic eruptions (IPSBE): (a) diagram of the modeling (1-4) and recording (5-14) IPSBE systems: (1) high-pressure gas tanks containing $\mathrm{CO}_{2}$ and $\mathrm{N}_{2}$, (2) sealed tank for preparing the model liquid, (3) transparent hose, (4) aquarium for disposal of the liquid, (5) the rope that directs the movement of the dynamic monitoring flatcar, (6) light source, (7) video camera, (8) transmitter and telemetry antenna, (9) microphone, (10) computer, (11) receiver of video signal and the monitor, (12) electric motor. An operator is at the top of this figure; (b) unit for preparing the gas-saturated model liquid and for supplying it to the transparent vertical hose.

to withstand a pressure of 5 atm. A valve system is operated to fill the tank with the liquid. In order for the liquid to be saturated with gas, a perforated tube with 50 holes was welded onto the lower part of the tank. The pressure in this system is measured by a pressure gauge that is installed at the top of the tank. A water-measuring column that is installed close to the tank over all of its height gives information on the liquid volume in the tank. A gas connection is welded onto the upper part of the tank; this connection plays the part of a squeezing piston. An emergency safety valve is used to ensure the safe saturation of the liquid with gas. This part of the device is effectively a saturator (a device that dissolves a gas in a liquid).

The experiments used a liquid (water) and two kinds of gas (carbon dioxide and nitrogen). Carbon dioxide $\left(\mathrm{CO}_{2}\right)$ readily dissolves in water $(828 \mathrm{ml} \mathrm{CO}$ is dissolved in 11 $\mathrm{H}_{2} \mathrm{O}$ at temperature $T=20^{\circ} \mathrm{C}$ and a pressure of $1 \mathrm{~atm}$ ); as well, this gas readily passes to or is released as a free phase [17]. Nitrogen $\left(\mathrm{N}_{2}\right)$ is used as a piston that squeezes the model liquid from the tank. This gas scarcely dissolves in water: only $18 \mathrm{ml} \mathrm{N}_{2}$ can be dissolved in 11 of $\mathrm{H}_{2} \mathrm{O}$ at temperature $T=20^{\circ} \mathrm{C}$ and $P=1$ atm [17]. Both of the gas containers that feed $\mathrm{CO}_{2}$ and $\mathrm{N}_{2}$ are equipped with reducers that control the gas discharge.

The "conduit/column." This part of the apparatus simulates the processes that occur in the conduit of a volcano. A stainless-steel tube goes from the lower part of the tank lateral wall in a horizontal direction; the tube gradually bends to assume a vertical direction instead of an axial one. The gradual bending prevents the generation of turbulence. The tube is equipped with a closing ball cock, which controls the supply of the model liquid from the tank into a plastic hose.

The top of the steel tube is connected to a transparent plastic hose, whose height (length) is $16600 \mathrm{~mm}$ and inner diameter is $18 \mathrm{~mm}$. The working cross-sectional ratio, i.e., the ratio of the inner diameter of the hose to its length (to height in this case), is approximately one to a thousand. This ratio is similar to the actual parameters of volcanic conduits.

A special bonding system maintains the hose in a vertical position. A measuring tape extends along the column graduated at steps of $1 \mathrm{~mm}$.

The tube, the ball cock, and the hose all have the same inner diameter. This, as well as the gradual tube bending, 
allows one to maintain laminar flow of the model liquid as it moves from the tank into the plastic hose.

The "crater/vent." The natural analogue to this part of the apparatus is a volcanic crater or a volcanic bocca. The top of the plastic hose is let into a transparent aquarium with a triangular cross section that is manufactured from organic glass. The top of the hose is cut perpendicularly to its axis $200 \mathrm{~mm}$ above the bottom. The aquarium is sealed so that the liquid does not penetrate outside the IPSBE. The aquarium is equipped with a sink.

The part of the modeling system described above allows one to keep track of processes that occur as liquid passes from the plumbing system into open space.

The recording system includes a dynamic video monitoring system, an electronic height indicator and velocity meter, a video recording unit, an acoustic recording unit, a synchronizing system, and a switching-off system (see Fig. 3a).

The dynamic video monitoring system is designed to carry out real time observation and recording of the processes that occur in the transparent plastic hose as the model liquid moves along it. A car with a video camera is moved along the hose on a set of guiding ropes. The car is moved by an electric motor. A powerful light source is installed on the car, which allows even very small inhomogeneities in the moving flow to be detected. The image obtained with the monitoring video camera is transmitted to the monitor via telemetry in real time. The operator, who keeps track of the video image, can use a control board for quick modification of car speed in the range from $2 \mathrm{~cm} / \mathrm{s}$ to $100 \mathrm{~cm} / \mathrm{s}$.

The altimeter and velocity meter. A special electronic unit was manufactured in order to determine the height and velocity of the moving car simultaneously. The unit can find the car's vertical position to within $10 \mathrm{~mm}$ with the altimeter and determine the change in its velocity (in the range $2 \mathrm{~cm} / \mathrm{s}$ to $100 \mathrm{~cm} / \mathrm{s}$ ) using the velocity meter.

Video recording. The experiment is recorded by a video camera, which is installed on the moving car and records the evolution of the model liquid that ascends along the transparent hose. For convenience of observation we fixed the optimal image capture angle, which allows a video sequence of moving bubbles in a $30-\mathrm{cm}$ height range.

The acoustic system records the sound signal that is produced when bubbles reach the surface of the model liquid and disintegrate. To do this, we installed a moistureprotected microphone above the top of the plastic hose, whose signal is digitally transmitted and stored on a computer. This is an analogue of a geophysical station that records vibrations arising in the immediate vicinity of the vent of an erupting volcano.

The synchronization unit. This part of the apparatus was manufactured for synchronizing video signals and acoustic signals to within a few milliseconds.

The emergency braking unit. The apparatus is equipped with a device for emergency stoppage of the car with the video camera in case the car goes outside the working zone.

The IPSBE is designed so as to allow its modeling system to be operated in two modes, viz., in a gas-saturated column (the model liquid with dissolved gas is fed into a tube) and in a sparging column (gas is injected into a tube with a liquid at rest, producing bubbles in the liquid). The modeling system is used without a "chamber zone" when operated in the sparging mode. The phase of bubble nucleation is then absent, but one can observe the behavior of the gas phase in an originally immovable liquid. The bulk of this study was conducted using a gas-saturated liquid. The experiments in the sparging column were not numerous and were done merely in order to compare them with those in the gas-saturated column. It should be emphasized that all IPSBE experiments involved an open system.

\section{EXPERIMENTAL WORK}

\section{Studies in a Gas-Saturated Column}

The preparation of the model liquid implies the saturation of 3501 water with $\mathrm{CO}_{2}$ gas. The saturation conditions were monitored by the pressure gauge. Some preliminary experiments were performed in order to select the optimal dissolution pressure, which was 1.6 technical atmospheres. This pressure value determined the starting release of the gas to the free phase from the lower part of the gas-saturated column and subsequently ensured that all gas-liquid regimes were maintained.

Before the experiment, the transparent hose was filled with water that was not yet saturated with gas. This provided stable conditions for the time the system was started. Simultaneously with this, the valve was opened to feed nitrogen from the gas container into the tank, and the ball cock was turned on to feed the model liquid from the tank into the plastic hose. The nitrogen created excess pressure in the tank and the ascending gas-saturated liquid squeezed out unsaturated water from the hose. While maintaining a low nitrogen discharge, we let the system become stabilized and began the experiment itself by observing the events that occurred in the transparent hose. The discharge of the gas-saturated liquid that entered the column during each experiment was kept constant.

These experiments showed that as the gas-saturated liquid was moving along the vertical column four different types of gas-liquid flow patterns occurred at different height intervals, viz., liquid, bubble, cluster, and slug types (Fig. 4). These flow patterns were persistent and were maintained as long as desired, each in its own height range, provided the discharge of the model liquid was kept constant. We provide a description of the experiment that is considered as the basic format, where all features of these flow patterns can be seen clearly at discharge rates of the model liquid that are equal to $3-5 \mathrm{~cm} / \mathrm{s}$. For convenience in describing the processes that occur in each height range, we will consider the first $30 \mathrm{~cm}$ of each meter 
(a)

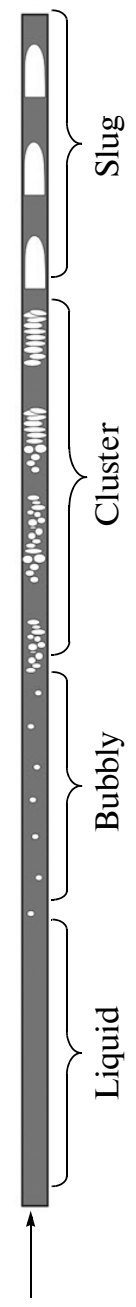

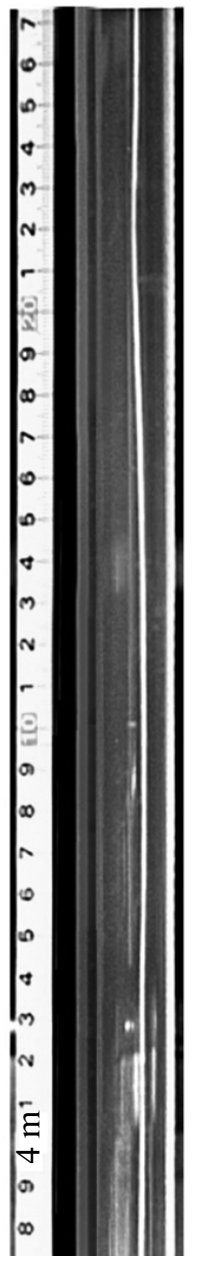

Liquid

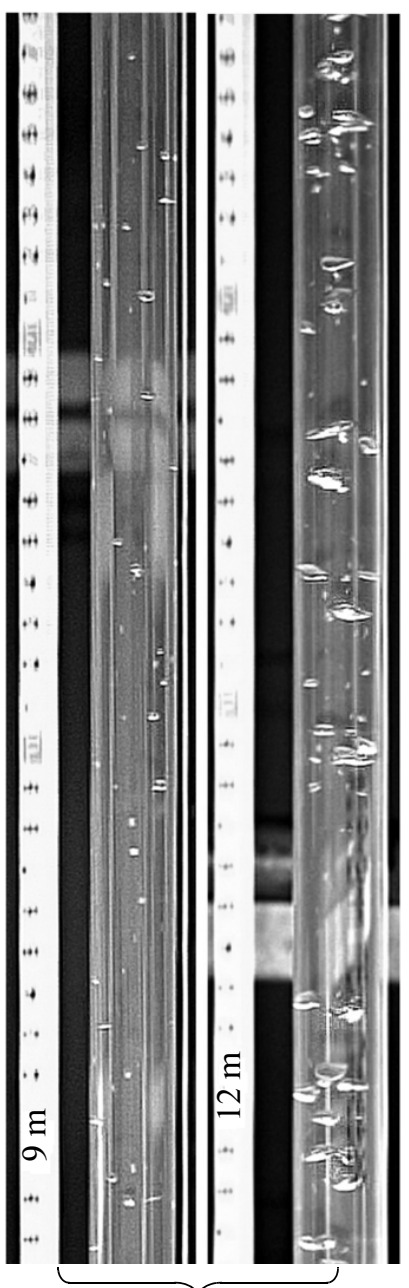

Bubbly (b)

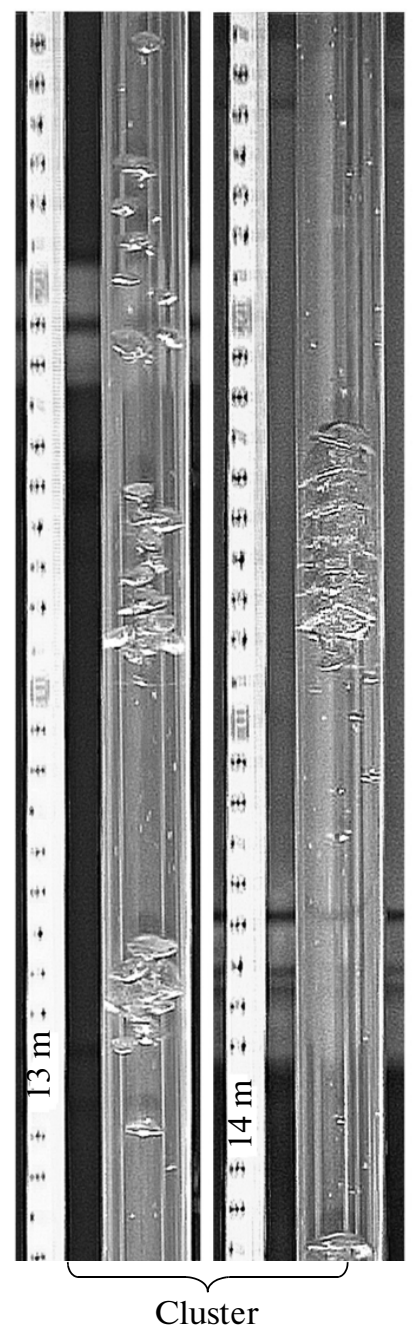

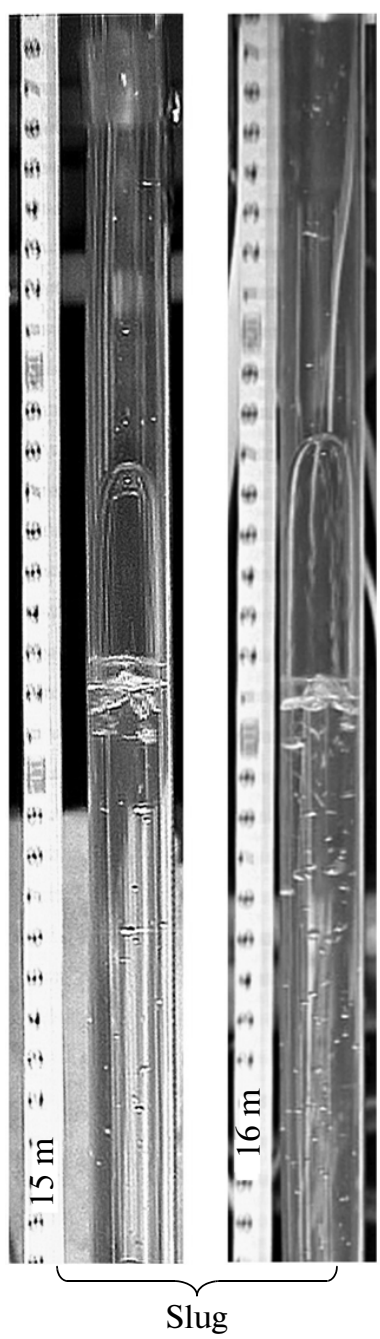

Fig. 4. Fragments of gas-liquid flow patterns arising during the ascent of the gas-saturated liquid in the vertical transparent hose: (a) schematic representation of gas-liquid flow patterns along the column, (b) video shots of flows in the gas-saturated model liquid rising in a vertical conduit. Left of the hose is a measuring tape with indication of height for each shot. All shots of the successively evolving model liquid were made during a single passage of the video camera along the column at the speed of the rising gas phase.

and tentatively extrapolate these events to the entire 1-m zone.

The liquid-flow pattern. The height range of this pattern in the vertical column is $0-4 \mathrm{~m}$ (from bottom upward). The model liquid rose along the hose together with the gas $\mathrm{CO}_{2}$ dissolved in it. This was a laminar singlephase flow, so the stream did not contain any inhomogeneities (see Fig. 4). The liquid flow did not involve bubbles and all gas was in a dissolved state. The model liquid was homogeneous, hence no displacement was recorded in the moving gas-saturated column in the height range considered. Decreasing pressure led to a rearrangement of the gas-saturated liquid, that is, it created conditions for the release of the gas phase.

The Bubble flow pattern. The height range of this pattern in the vertical column was 5-12 m (see Fig. 4). The bubble flow pattern arose when the first bubble was generated. From this time the column showed a two-phase flow of the model liquid. The transition to the bubble flow was almost imperceptible. Barely noticeable $(<1 \mathrm{~mm})$ bubbles were generated in the liquid. At first, the nucleation of bubbles was very slow, with only some isolated bubbles being observed in the lower part of the column $(5-7 \mathrm{~m})$. Subsequently, the nucleation rate increased to reach 60 bubbles at the 11 th meter. The bubbles that were generated were smaller than $1 \mathrm{~mm}$ throughout the column. Higher, where the transition to the next flow pattern was to take place, the bubbles that were formed in the lower parts of the bubble flow reached diameters as great as 7$9 \mathrm{~mm}$ in. The bubbles exchanged places as they moved, were accelerated or retarded in motion, and expanded. No coalescence of bubbles was observed. As the liquid 
rose, more and more new bubbles were generated (see Fig. 4). As a result, the upper parts of the bubble flow height range contained several bubble generations or, to be more exact, a gradual transition from smaller (newly formed) to larger bubbles occurred (which were generated previously at lower elevations).

The bubble distribution over the column was as follows. At first, in the lower part of the column, the distribution was sufficiently uniform, while higher, in some height ranges, compact accumulations (swarms) of bubbles occurred, while the other parts were rarefied. The initial bubble velocity was $25-30 \mathrm{~cm}$ relative to the tube walls and increased to reach $40 \mathrm{~cm} / \mathrm{s}$ as the bubbles rose.

The cluster flow pattern. The range of this pattern in the column was 13-14 m (see Fig. 4). The bubbles became more numerous and larger in size and this led to a structural rearrangement of the gas-liquid flow; the distances between individual bubble swarms appreciably increased and the swarms became more dense. The result was the formation of well-pronounced bubble swarms, which were transformed into definite structures during the subsequent ascent of the model liquid; the structures were a kind of bubble cluster that usually consists of 20-35, and occasionally as many as 50, near bubbles (see Fig. 4). The clusters were separated from one another by a liquid layer that was nearly devoid of the free gas phase. The clusters were $2-3$ tube diameters long $(30-55 \mathrm{~mm})$; the intercluster space was 7-9 tube diameters $(120-160 \mathrm{~mm})$. We usually could observe about 10 clusters that simultaneously existed in the experimental column; the clusters moved one after another at a fixed distance. The cluster velocity relative to the tube wall was $\sim 35 \mathrm{~cm} / \mathrm{s}$. In a mature cluster flow the bubbles had a combined convex/concave shape and were, as it were, embedded in one another, resulting in a remarkable dynamic and very dense gas packing.

We successively generated two types of bubble clusters (see Fig. 4). In the lower part of the cluster flow $(13 \mathrm{~m})$ we had "open" clusters, which became "blocked" as they rose. The open clusters consisted of bubbles of similarvalued diameters; discrete bubbles exchange places during the movement, either passing or falling behind one another. A blocked cluster is a set of bubbles that follow a single larger one. The morphology of blocked clusters is such that they are squeezed to the inner tube wall throughout their extent, thus filling out nearly all of the tube diameter.

The slug flow pattern. The range of this flow pattern was $15-16.6 \mathrm{~m}$ (see Fig. 4). The subsequent structural rearrangement of the two-phase mixture was due to the rupture of interbubble walls as a consequence of their being squeezed together in a cluster. A large bubble formed in the top of the cluster (coalescence proceeding downward) and after some time the cluster became a distinct slug 3-4 tube diameters long (see Fig. 4). Each slug occupied nearly an entire cross section; it was adjacent on its lateral side to the inner surface of the tube, so that a thin, nearly indistinguishable, circular gap for reverse liquid flow remained. Considered relative to the surrounding liquid, these slugs were large gas cavities. As they rose, they became longer, and the smaller bubbles that followed in their wake became more numerous. On the whole, however, the slugs did not experience any great morphological changes.

The column was observed to contain about 10 slugs simultaneously; these moved one after another at a fixed distance, producing a peculiar beaded structure. The slug burst on reaching the surface; each splash of the model liquid corresponded to the emergence of a slug. This can be clearly illustrated by the acoustic record made by the IPSBE (Fig. 1c). The background signal level corresponded to the discharge of a definite volume of the model liquid that separated the gas slugs. The slugs moved somewhat faster than the clusters, about $40 \mathrm{~cm} / \mathrm{s}$. The slug flow pattern was the most persistent among the gas flows studied here; the slug volume and interslug distance were nearly constant until reaching the top of the tube.

The above description corresponds to the condition at which the gas saturation pressure in the tank was $1.6 \mathrm{~atm}$ and the rate of model liquid supply into the vertical column was $3-5 \mathrm{~cm} / \mathrm{s}$. With this gas saturation pressure we conducted a series of experiments in a wide range of model liquid supply rate (from $1 \mathrm{~cm} / \mathrm{s}$ to $10 \mathrm{~cm} / \mathrm{s}$ ). The general structure of the gas-liquid flow and the transition from one flow pattern to another remained similar to those obtained in the main experiment, as described above.

At lower gas saturation pressures, the gas phase was released later, at a higher level in the column, and the gassaturated flow could not pass through the complete evolutionary sequence of all flow patterns that were obtained in the main experiment. The gas phase did not have sufficient time to allow it to be released from the model liquid at a low pressure $(0.3-0.4 \mathrm{~atm})$ and liquid flow was observed at the surface. Increasing saturation pressure in the tank results in ever more advanced flow patterns appearing at the surface in each next experiment. Thus, any of the four flow patterns described above is dependent on the conditions of gas dissolution in the liquid and could be made to appear at the surface, at the top of the hose. This permits simulation of different types of volcanic eruptions.

Studies in the Sparging Column. The experiments conducted with the IPSBE showed that a column with a liquid at rest exhibits the same effects of bubble structuring as those in the gas-saturated column described above. Gas clusters were generated from a uniformly rising bubble flow, and these clusters were transformed into slugs during their movement. In this way the sparging option can create three flow patterns, viz., bubble, cluster, and slug patterns.

\section{DISCUSSION OF RESULTS}

(I). The IPSBE experiments add significantly to the available gas-hydrodynamic concepts which form the basis of volcanological constructions related to the move- 
ment of basaltic melts. This is due to the following reasons.

(1) A model was created for the first time that incorporated the geometric parameters of the conduit of a basaltic volcano. The longitudinal extent of actual volcanic conduits is several orders of magnitude greater than their diameter, so in our IPSBE experiments we used approximately the value $1: 1000$ for the ratio between the inner diameter of a conduit and its height.

(2) For the first time in the physical modeling of eruptions, we have managed to maintain the conditions for the ascent of a gas-saturated liquid along the column, which provided opportunities for observing the nucleation of gas bubbles, their subsequent expansion, and the generation of clusters and slugs.

(3) The model liquid was made to ascend at a uniform speed, with any structural barriers and fluctuations in the supply rate of the gas-saturated liquid being ruled out.

(II). The experiments used a single-phase model liquid; as this liquid rises in a long vertical column, the liquid transforms itself into a two-phase system (water-gas). The successive (from bottom upward) four gas-liquid flow patterns include liquid, bubble, cluster, and slug flows, which replace one another successively (see Fig. 3).

The generation of gas-liquid flow patterns begins from the time the first bubble formed in the liquid and continues until the mature slug flow appears. There is a well-pronounced evolutionary sequence: dissolved gas $\longrightarrow$ gas bubble $\longrightarrow$ bubble cluster $\longrightarrow$ gas slug. The manifestation of gas-liquid polymorphism occurs. Modern science defines polymorphism as the capability or property of a substance, whether simple or compound, to give rise to two or more modifications under different thermodynamic conditions; the modifications have the same chemical composition, but different physicochemical properties. Modifications or different forms of one and the same substance are called polymorphous modifications. Our experiments show that a substance of one and the same composition (water with dissolved carbon dioxide) acquires quite different forms as it evolves. We thus deal with a well-pronounced gas-liquid polymorphism. In that case the flow patterns identified (liquid, bubble, cluster, and slug) should be viewed as polymorphous modifications; the general structure of the moving liquid should be treated as a polymorphous flow and the movement itself as polymorphous flow.

(III). Our experimental studies revealed a previously unknown link between the bubble and the slug flow patterns. This is a new and morphologically persistent gasliquid flow. We suggest calling it a cluster flow (see Fig. 4). This flow pattern has not been described either in monographs $[14,34,55]$ or in publications dealing with the simulation of oil well operation using a large apparatus [1,22].

The main characteristics of the cluster flow pattern are as follows: (1) the leading element is the bubble cluster, which is a volume of liquid with a high concentration of bubbles that is separated from below and from above by a liquid with no free gas phase; (2) a set of bubble clusters moving one after another at a definite distance produces the cluster flow that is invariably seen between the bubble and the slug flow; (3) cluster structures in separate height ranges along the column are persistent in character, they repeat themselves; (4) morphologically, we distinguish between clusters of two types, open and blocked; (5) the clusters rise more slowly compared with large bubbles and slugs; (6) the lifetime of a cluster flow is comparable with the existence time of the bubble and slug flows; (7) the cluster flow arises in a wide range of hydrodynamic conditions: in a sparging column (with zero speed of the liquid and with no dissolved gas) and in a gas-saturated column (in the range of liquid speed $1-10 \mathrm{~cm} / \mathrm{s}$ ); (8) the mechanism that is responsible for generating the clusters occurs due to the interaction between large gas structures and the conduit walls and to self-blocking and retardation.

The present author believes that the cluster flow pattern does not occur in volcanic phenomena alone. This flow pattern should be treated in its own right in the physics of gas-liquid mixtures, for example, in natural features (hydrothermal systems and mud volcanoes), in the simulation of drilled well operation (in hydrothermal and oil wells), and in the chemical industry.

(IV). The mechanism that is responsible for the generation of a cluster flow seems to be as follows (see Fig. 4). The embryos of future clusters are seen distinctly in the top part of the segment of the column where the bubble flow occurs. Here one observes a nonuniform distribution of bubbles with distinguishable bunches or concretions consisting of discrete bubbles. As the cluster flow pattern begins to form, these separate groups become more pronounced. A large bubble or a concretion of smaller bubbles begin at some moment to interact with the conduit walls. Subsequent expansion of the bubbles leads to an appreciable reduction in the cross section of the reverse liquid flow in the annulus between the gas structure in question and the conduit walls. Self-blocking occurs as a consequence, which retards the movement of the bubble or the bubble concretion. As a result, the speed of their movement is reduced and it (they) becomes a kind of "plug" for the bubbles that rise from below. The latter are accumulated under the plug, the distance between them decreases, and a new gas structure is formed from a great number of bubbles, viz., a bubble cluster. The bubbles that are situated above the incipient cluster in the column continue their movement at the same speed and rise away from the cluster, thus creating a volume of the liquid without gas bubbles above the cluster. Under the cluster too, one also has a volume of liquid that is devoid of gas bubbles because of a new gas cluster that is being generated at a lower height.

(V). Clusters are converted into slugs in the top of that segment where the mature cluster flow pattern typically occurs. The conversion only occurs in blocked clusters where the bubbles are compacted together and touch the inner conduit walls with their lateral edges. This very 
dense dynamic packing inevitably results in coalescence, so that a larger gas bubble is generated from bubbles in the top of the cluster. The bubbles begin to coalesce (slug generation); the coalescence occurs from top to bottom in the cluster, so after some time the gas cluster turns into a classical gas slug.

The slug flow pattern turned out to be the most stable pattern in the conditions of the present experiment. The pattern can persist as long as desired and does not turn into any other pattern, but the parameters of this pattern undergo certain changes during the ascent. For example, decreasing hydrostatic pressure induces gas diffusion from the model liquid into a slug, thus making it longer and increasing the speed of its motion. A rarefied zone occurs in the bottom of the slug, as can be inferred from its concave (upward) meniscus. The model liquid becomes more turbulent under the slug. A new nucleation phase begins to produce much more numerous small bubbles in the wake of the slug. The slug flow pattern is thus divided into two well-pronounced subpatterns, viz., the pure slug with nearly no gas bubbles in its wake and the mature slug flow, where a slug is followed by a train of small bubbles.

(VI). The experimental studies that are reported here gave the result that the gas phase can be structured as far as producing gas clusters and slugs in a wide range of velocity and under different gas-liquid conditions. This is indicated by two variants of experiments conducted on the IPSBE: using a gas-saturated column (with a speed of liquid movement between 1 and $10 \mathrm{~cm} / \mathrm{s}$ ) and a sparging column (the gas emerges in bubbles through a liquid at rest). In both of these cases we observed one and the same sequence of gas phase structuring: gas bubble $\longrightarrow$ gas cluster $\longrightarrow$ gas slug. The gas structures thus passed successively through one and the same morphologic evolution. This shows that the gas structures identified here necessarily occur in vertical gas-liquid systems in a rather wide velocity range. It can therefore be presumed that the gas phase in actual basaltic conduits follows the same path of structural evolution as in the experiments we made.

(VII). We have considered the manifestation of each gas-liquid flow pattern at the top of the tube, since it is in this part of the IPSBE that the processes are simulated that typically occur in the vent zone of basaltic volcanoes. Depending on the amount of dissolved gas in the model liquid, any of the flow patterns described above can be made to reach the surface. We compared the surface effects of each flow pattern with the actual dynamic parameters of basaltic eruptions (see Figs. 4, 5).

The liquid flow pattern. Gas is not found as a free phase; the model liquid is uniformly discharged through the top of the tube. The liquid flow pattern corresponds to a uniform (no explosions) discharge of lavas in the crater zone of a volcano.

The bubble flow pattern is due to a uniform flow of bubbles that explode at the surface of the liquid. The manifestations of this flow pattern during a basaltic eruption may be rather diverse in character and scale, depending on the number of bubbles, their size, and magma viscosity.
In liquid magmas one may observe weak "boiling" at the surface of a lava lake or weak spouting in the vent, while magmas of higher viscosity give rise to uniform, constant ash emission due to bursting of membranes between bubbles that reach the surface. The leading feature of this flow pattern is a uniform supply of gas bubbles that rise to the surface over a long period.

The cluster flow pattern is characterized by discrete "splashes" of the model liquid at the outlet of the conduit due to the appearance of bubble clusters, with the splashes alternating with quiet discharge of the model liquid. The cluster flow gives rise to quasiperiodic generation of expanding bubbles or splashes of discrete lava spouts when it occurs in liquid magmas in the crater zone of a volcano. When the melt has a higher viscosity, ash discharges without bombs or with a small number of bombs occur (Fig. 6a). The generation of volcanic bombs is due to the decreasing thickness and fracture of the upper magma layer above a cluster and to the removal of major "membranes" in the layer; the fine tephra fraction (volcanic ash) forms by fracture of thin walls of smaller bubbles that make up the cluster. When the cluster flow is in the mature phase, these phenomena are more violent and spectacular.

The slug flow pattern occurs when the outlet of the conduit is characterized by violent splashes of the model liquid due to fracture of the liquid layer above gas slugs that have reached the surface. Splashes alternate with quiet emission or ascent of the liquid along the column (see Fig. 4). There are two phases of the slug flow pattern. The first is slug flow proper, during which the liquid contains nearly no small bubbles behind the gas slug; the second phase is the slug-train phase, where the slug is followed by a persistent train of small bubbles. The manifestations of the slug phase proper during volcanic eruptions in liquid magmas consist of "popping-up" lava bubbles (see Fig. 6b) and violent discharges of liquid lava. Magma melts of higher viscosities exhibit rapid fracturing in the top of a slug at the surface, producing discrete violent bomb ejections. When in the slug-train phase, bomb ejections are accompanied by the emission of volcanic ash, which is produced by the large number of small bubbles that follow the slug.

When in the crater zone, the manifestations of the cluster and the slug flow patterns are similar (lava bubbles, splashes, bomb ejection, and volcanic ash), but considerable differences also exist. These are due to the internal structure of the gas formation. A cluster is a foamy cell structure in which the bubbles are separated by membranes from one another; the membranes make a general framework that fills the entire body of the cluster. In contrast to a cluster, a gas slug is a single gas cavity. As a cluster reaches the surface, the membranes experience multiple fractures. Depending on the foam size (bubble size in the cluster), there will be ash or bomb-ash discharges at the surface. In contrast to a cluster, a gas slug is a single gas cavity that is seen at the surface as a one-pulse fracture of the upper magma layer; volcanic bombs are mostly the result. 


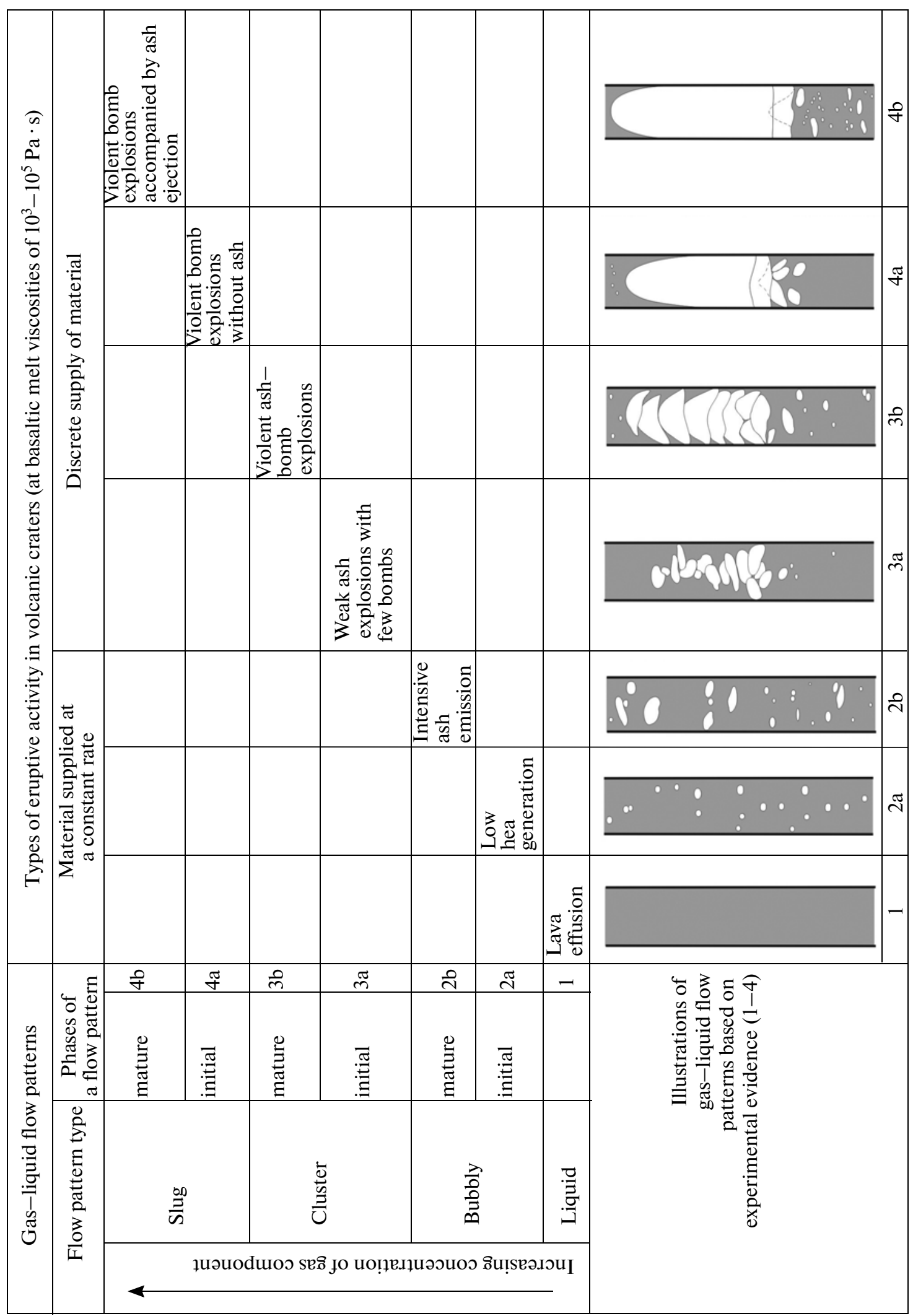

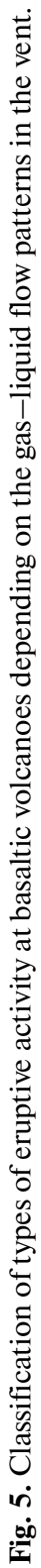




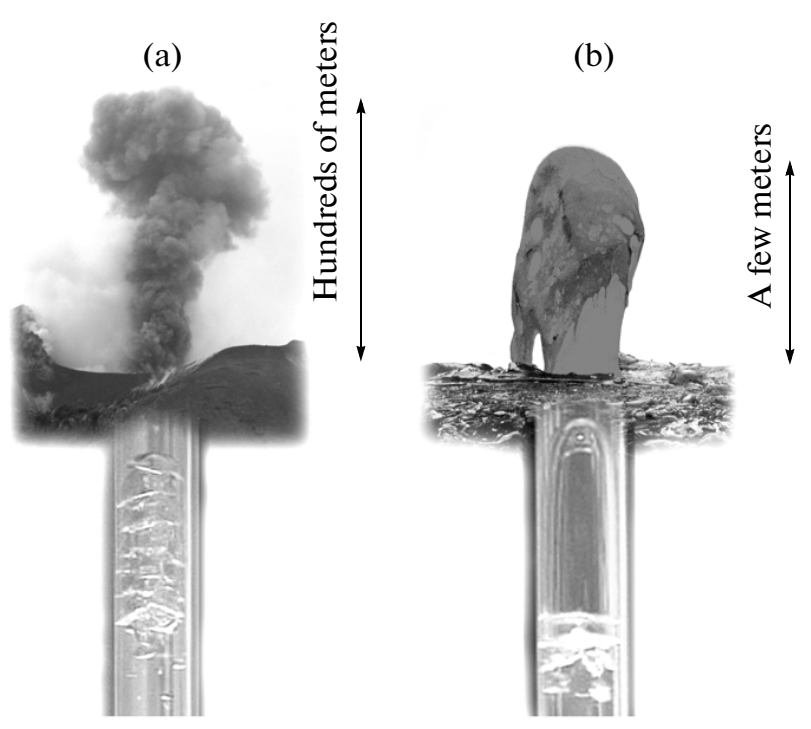

Fig. 6. A model demonstrating the origin of explosive discharges/explosions as a cluster or a slug flow comes to the surface. Bottom: the gas structures identified during the IPSBE experiments, top: actual volcanic events: (a) ash ejection at Stromboli Volcano, 2004, photographed by A.Yu. Ozerov, (b) lava bubble [35].

The generation of cluster and slug flow patterns leads to a significant rearrangement of the potential energy in the magma column; with increasing melt viscosity, all other things being equal, the intensity of the gas pulse is considerably greater and actually reaches the explosion phase.

(VIII). In physics, the shock wave that is produced by the discharge or expansion of material is considered to be the main criterion for any explosion [12, 21]. The shock waves that arise during explosions at many volcanoes were described by V.V. Adushkin et al. [2]. Such waves were recorded by P.P. Firstov, V.V. Adushkin, and A.V. Storcheus [25, 29, 30, 32] for Klyuchevskoi Volcano (the 1983 and 1987 eruptions) and on Tolbachik (the 1975-1976 eruption). They used acoustic recording instruments to distinguish between five types of shock wave that are produced by volcanic discharges and assumed that the impulsive signals that result from discharges of magmatic material are low-density shock waves. Their analysis of shock wave parameters for Klyuchevskoi and Tolbachik volcanoes gave the discharge energy, which was estimated to be approximately $10 \mathrm{t}$ of TNT for smaller explosions and $100 \mathrm{t}$ of TNT for larger ones. In the cases considered above (Klyuchevskoi and Tolbachik), shock waves were observed for viscosities of the magma melt that were equal to $10^{3}-10^{5} \mathrm{~Pa}$ s. It is exactly at these viscosities that the membranes in a cluster or in the layer of magmatic material above a slug retain plastic properties during ascent in a conduit, but when the cluster or the slug comes to the surface and the potential energy of compressed gas is instantaneously released the membranes behave as solids, which produces shock waves.
(IX). We compared the acoustic record of a slug flow at the top of the IPSBE experimental column with a seismic record of explosive activity at the summit crater of Klyuchevskoi Volcano. Figures $1 \mathrm{~b}$ and $1 \mathrm{c}$ reveal certain common features in the experimental and the natural signals. In both of these cases they reflect discrete, quasiperiodic processes with different amplitudes. This suggests that the gas-liquid processes that are produced in the IPSBE and those that occur in actual magma-conducting systems are of the same origin.

It should be noted that the recording of events that occur on Klyuchevskoi and in the IPSBE was carried out using different methods, viz., seismic and acoustic methods, respectively. The trains of explosions of basaltic magma recorded by the two methods usually differ in train duration, with the acoustic signal being much shorter compared with the seismic signal. The background signal is usually low. In the IPSBE the higher acoustic background (see Fig. 1c) results from the fact that the recording microphone is close to the source of sound, i.e., to the top of the tube where the model liquid is continually discharged, thus giving a high background level. If the events could be recorded by similar methods to reduce the background amplitude of the flowing model liquid, then the volcanic and simulated records would undoubtedly be more similar.

(X). Several scenarios emerge for the mechanism that is responsible for the explosions of basaltic magma based on knowledge of the energies of large discrete explosions, magma viscosity, and the results of our experiments (see Fig. 5): (1) weak ash explosions with few bombs or without them, which is the initial phase of the cluster flow; (2) large ash-bomb explosions: the cluster flow; (3) bomb explosions: the slug flow proper; (4) bomb explosions becoming ash explosions: the mature slug-train flow accompanied by a train of small bubbles. Increasing the amount of the gas phase in a flow thus leads at first to an increasing amount of ash (the bubble and cluster flow patterns), then to a decrease (the slug flow), and subsequently to an increase again (the slug-train flow pattern). The data adduced above demonstrate that different types of gas-liquid flows that arise in gas-saturated melts that rise in long vertical column are responsible for different manifestations of Strombolian activity on basaltic volcanoes.

(XI). A new definition of one of the basic concepts in volcanology, the explosion of basaltic magma, emerges from our study of the origin of the cluster and slug flow patterns and from the comparison between these and field observations on basaltic volcanoes.

An explosion of basaltic magma is a very rapid release of energy that produces a discrete discharge to the surface of a considerable volume of volcanic gas and disintegrated magma melt of low viscosity $\left(10^{3}-10^{5} \mathrm{~Pa} s\right)$. The mechanism that is responsible for the generation of large separate gas accumulations occurs due to polymorphous gas-liquid changes in the vertical magmatic conduit. As the hydrostatic pressure decreases, the gas-saturated melt that rises along the conduit passes through four flow patterns, 
the liquid, bubble, cluster, and slug patterns. All these occur in eruptions of basaltic volcanoes. The appearance of a cluster or slug flow leads to a sequence of explosions. Explosions such as these are known to have occurred on Klyuchevskoi, Tolbachik, Stromboli, Etna, Mt. Erebus, and other volcanoes. The average explosion of basaltic magma ejects 30-100 t magma melt to the surface.

An analysis of our data suggests that, however tempting it would appear to pass from the IPSBE modeling apparatus to an actual basaltic plumbing system by using physical equations, as well as dimensionless quantities on the lines of $[15,23]$, it is rather difficult to do so at present. This is due to several factors, including the fact that the cluster flow pattern that is described in the present publication for the first time has not yet been formalized mathematically.

\section{CONCLUSIONS}

(1) An instrument package for simulating basaltic eruptions (IPSBE) was developed for investigating the movement of magma melt in the plumbing system of a volcano. The apparatus was designed in order to study the processes that occur during the formation, ascent, and appearance at the surface of a two-phase gas-liquid flow moving along a vertical channel.

(2) The analysis of diverse flow patterns that arise in one and the same model liquid showed that the four flow patterns (the liquid, bubble, cluster, and slug patterns) arise as a result of successive evolution of a gas-saturated flow and have well-defined morphologic features of their own. This indicates a structural gas-liquid polymorphism of liquid flow, so that the flow patterns that are identified are accordingly polymorphous modifications of a gas-saturated flow.

(3). Our experiments revealed a new and previously unknown flow pattern of two-phase mixtures in a vertical column, the cluster flow; this is characterized by a pattern of alternating dense accumulations of gas bubbles (clusters) separated by liquid that does not contain a free gas phase. The mechanism that is responsible for cluster generation functions due to interaction between larger gas structures and the conduit walls, giving rise to self-blocking and retardation, so that a relatively slow-moving gas plug arises, a cluster.

(4) Our studies suggest a new model for the gas-liquid evolutionary movement of a magma melt in the conduit of a basaltic volcano. The different flow patterns that appear at the surface of a two-phase mixture are responsible for the diversity of explosive phenomena that occur in the volcanic crater. Depending on which flow pattern occurs in the volcanic vent, a uniform or discrete supply of magmatic material may occur; for the former there will be a discharge of lava and continuous ash emission, while the latter will produce ash, bomb, or ash-bomb explosions.

(5) An analysis of the factors that influence the appearance of the main explosive forms in basaltic magma in a volcanic vent provided an explanation in terms of gas-liq- uid flow patterns: (1) weak ash explosions with few bombs: the initial phase of the cluster flow, (2) large ash-bomb explosions: the mature cluster flow, (3) bomb explosions: the slug flow, initial phase, (4) bomb explosions passing into ash explosions: mature gas slugs accompanied by trains of small bubbles.

(6) This study of explosions as they occur on basaltic volcanoes along with new experimental evidence provided a basis from which to determine the mechanism that is responsible for the preparatory period before explosions of basaltic magmas, which are understood as a process of gas-liquid transformation of the magma melt that rises along a vertical volcanic conduit.

\section{ACKNOWLEDGMENTS}

The author is sincerely grateful to V.A. Droznin for his long-continued aid in this research. Considerable aid was also received from the Managing Board of the Institute of Volcanology and Seismology, Far East Division, Russian Academy of Sciences (RAS): academician of the RAS E.I. Gordeev, academician S.A. Fedotov, Ya.D. Murav'ev, G.A. Karpov, N.I. Seliverstov, V.A. Kazantsev, V.N. Chebrov as General Manager of the Kamchatka Branch of the RAS Geophysical Service; we also acknowledge the aid rendered by I.R. Abubakirov, G.P. Avdeiko, M.A. Alidibirov, G.I. Anosov, Yu.A. Babushkin, A.B. Belousov, V.I. Belousov, G.E. Bogoyavlenskaya, O.E. Bograd, K.A. Bychkov, A.V. Butkach, G.F. Vasil'ev, T.D. Vislova, M.G. Gavrilenko, A.A. Gavrilov, V.A. Gavrilov, V.I. Guseva, N.S. Danilevich, Yu.V. Demyanchuk, O.I. D'yachkova, D.V. Droznin, Yu.M. Dubik, R.L. Dunin-Barkovskii, I.K. Dubrovskaya, V.N. Dubrovskii, V.I. Dyadin, V.V. Ivanov, Jr.,Ya.O. Ispolatov, S.V. Kas'yanov, V.A. Kirichenko, A.S. Konov, D.Yu. Kuz'min, Yu.D. Kuz'min, A.V. Lander, V.L. Leonov, S.F. Laktionov, V.S. Lutaya, A.P. Maksimov, V.K. Marynova, M.A. Mokhov, A.A. Mul'keev, A.V. Mushinskii, A.E. Nazarov, A.A. Nuzhdaev, N.A. Ozerova, N.A. Ozerova, Jr., L.G. Osipenko, I.L. Ototyuk, V.K. Panov, S.I. Plotnikov, E.G. Ponomarev, V.G. Pushkarev, A.A. Razina, V.A. Rashidov, A.N. Rogozin, N.V. Romanov, I.Yu. Svirid, S.L. Senyukov, V.A. Sergeev, V.V. Sergeev, A.V. Sokorenko, A.V. Storcheus, I.F. Timofeeva, G.P. Timoshenko, A.P. Khrenov, V.N. Shapar', V.A. Shirokov, V.P. Shpak, V.S. Shul'ga, O.V. Fedoristov, P.P. Firstov, Yu.V. Frolova, I.V. Chaplygin, O.V. Chaplygin, S.A. Chirkov, O.S. Chubarova, and V.A. Churikov.

Great help was also received from the Administration of Kamchatka Krai through Assistant Chairman of the Government V.N. Karpenko, as well as A.A. Gavrilov, L.A. Grachev, and S.I. Kravets.

The author wishes to express his sincere gratitude to colleagues abroad who provided help: J. Eichelberger, P. Joyless, F. Keil, and J. Lees.

Great help during the preparation of the manuscript was rendered by academician V.I. Kovalenko, academician V.V. Adushkin, Prof. Yu.D. Chashechkin, 
Prof. N.N. Sysoev, and Doctor (Phys.-Math.) A.A. Gusev.

This work was supported by the Russian Foundation for Basic Research, grant no. 09-05-00841-a and by a grant from the Government of Kamchatka Krai.

\section{REFERENCES}

1. Abishev, S.K., Bulgakov, R.R., and Sakharov, V.A., An Experimental Installation for Investigating the Movement of Gas-Liquid Mixtures in Vertical Tubes in Application to the Ascent of High Viscosity Oil, Tr. MINKh i GP, 1981, no. 156, pp. 98-104.

2. Adushkin, V.V., Gostintsev, Yu.A., and Firstov, P.P., On the Origin of Air Waves Due to Large Explosive Eruptions, Vulkanol. Seismol., 1984, no. 5, pp. 3-11.

3. Ariskin, A.A., Barmina, G.S., Ozerov, A.Yu., and Nielsen, R.L., The Genesis of Klyuchevskoi High Alumina Basalts, Petrologiya, 1995, vol. 3, no. 5, pp. 42-67.

4. Balesta, S.T., Ivanov, B.V., Utnasin, V.K., et al., Crustal Structure in the Klyuchevskoi Group of Volcanoes Area, Tectonic and Volcanic Features, in Glubinnoe stroenie $i$ sovremennaya deyatel'nost' Klyuchevskoi gruppy vulkanov (The Deep Structure and Present-Day Activities of the Klyuchevskoi Group of Volcanoes), Vladivostok, 1976, pp. 6-15.

5. Vlodavets, V.I., Spravochnik po vulkanologii (A Handbook of Volcanology), Moscow: Nauka, 1984.

6. Gordeev, E.I., Mel'nikov, Yu.Yu., Sinitsyn, V.I., and Chebrov, V.N., Volcanic Tremor of Klyuchevskoi Volcano: The 1984 Eruption at the Summit Crater, Vulkanol. Seismol., 1986, no. 5, pp. 39-53.

7. Gorel'chik, V.I., Seismic Manifestations of Volcanic Activity, in Glubinnoe stroenie i sovremennaya deyatel'nost' Klyuchevskoi gruppy vulkanov (The Deep Structure and Present-Day Activities of the Klyuchevskoi Group of Volcanoes), Vladivostok, 1976, pp. 108-118.

8. Gorshkov, G.S., On the Depth to the Magma Chamber of Klyuchevskoi Volcano, Dokl. AN SSSR, 1956, vol. 106, no. 4, pp. 703-705.

9. Droznin, V.A., On the Origin of Volcanic Eruptions, in Mater. 1 gorodskoi konferentsii molodykh uchenykh $i$ spetsialistov (Proc. 1st City Conf. of Young Scientists and Specialists), Petropavlovsk-Kamchatskii: Dal'nevostochnoe knizhnoe izdatel'stvo, 1969, pp. 4-6.

10. Droznin, V.A., Fizicheskaya model' vulkanicheskogo protsessa (A Physical Model of the Volcanic Process), Moscow: Nauka, 1980.

11. Kozlov, B.K., The Regimes and Forms in the Movement of an Air-Water Mixture in a Vertical Tube, in Gidrodinamika $i$ teploobmen pri kipenii $v$ kotlakh vysokogo davleniya (Hydrodynamics and Heat Transport during Boiling in High Pressure Boilers), Moscow: AN SSSR, 1955, pp. 7-18.

12. Kobylkin, I.F., Selivanov, V.V., Solov'ev, V.S., and Sysoev, N.N., Udarnye i detonatsionnye volny. Metody issledovaniya (Shock and Detonation Waves: Methods of Study), Moscow: FIZMATLIT, 2004.

13. Konov, A.S. and Ozerov, A.Yu., Patterns Observable in the Eruptions of Klyuchevskoi Volcano and in Accompanying Volcanic Tremor, Vulkanol. Seismol., 1988, no. 3, pp. 21-38.
14. Kutateladze, S.S. and Nakoryakov, V.E., Teplomassoobmen $i$ volny $v$ gazozhidkostnykh sistemakh (Heat-and-Mass Transfer and Waves in Gas-Liquid Systems), Novosibirsk: Nauka, 1984.

15. Landau, L.D. and Lifshits, E.M., Mekhanika sploshnykh sred (The Mechanics of Continua), Moscow-Leningrad: Gostekhizdat, 1944.

16. Luchitskii, I.V., Osnovy paleovulkanologii (Principles of Paleovolcanology), vol. 1, Sovremennye vulkany (PresentDay Volcanoes), Moscow: Nauka, 1971.

17. Namiot, A.Yu., Rastvorimost' gazov v vode (The Solubility of Gases in Water), Moscow: Nedra, 1991.

18. Ozerov, A.Yu., An Experimental Installation for Simulating Basaltic Explosions, in Mater. ezhegodnoi konf. posvyashch. dnyu vulkanologa (Proc. Annual Conf. Devoted to the Volcanologists' Day), 28-31 March, 2007, Petropavlovsk-Kamchatskii, 2007, pp. 144-156.

19. Ozerov, A.Yu., Ariskin, A.A., and Barmina, G.S., Concerning the Problem of Genetic Relationships between High Alumina and High Magnesium Basalts for Klyuchevskoi Volcano, Kamchatka, Dokl. RAN, 1996, vol. 350, no. 1, pp. 104-107.

20. Ozerov, A.Yu., Ariskin, A.A., Kail, F., et al., A PetrologicGeochemical Model for the Genetic Affinity between Basaltic and Andesitic Volcanisms: Klyuchevskoi and Bezymyannyi Volcanoes, Kamchatka, Petrologiya, 1997, vol. 5, no. 6, pp. 614-635.

21. Politekhnicheskii slovar' (A Polytechnical Glossary), Moscow: Sov. Entsiklop., 1976.

22. Sakharov, V.A. and Mokhov, M.A., Gidrodinamika gazozhidkostnykh smesei $v$ vertikal'nykh trubakh i promyslovykh pod"emnikakh (The Hydrodynamics of Gas-Liquid Mixtures in Vertical Tubes and Mining Elevators), Moscow: Neft' i Gaz, 2004.

23. Sedov, L.I., Metody podobiya i razmernosti $v$ mekhanike (Similarity and Dimensional Analysis in Mechanics), Moscow: Nauka, 1987.

24. Sorokin, Yu.L., On the Conditions of Stability for Some Flow Patterns in Gas-Liquid Mixtures Moving in Vertical Tubes, Prikladnaya Mekhanika i Teoreticheskaya Fizika, 1963, no. 6, pp. 160-165.

25. Storcheus, A.V. and Samoilenko, B.I., A Study of Volcanic Explosions during the Tolbachik Eruption with the Help of Movie-Taking, Vulkanol. Seismol., 1983, no. 5, pp. 102-106.

26. Fedotov, S.A., Magmaticheskie pitayushchie sistemy i mekhanizm izverzhenii vulkanov (Magmatic Feeding Systems and the Mechanism of Volcanic Eruptions), Moscow: Nauka, 2005.

27. Fedotov, S.A., Klyuchevskoi Volcano: Magma Source and Eruptive Mechanism, Vulkanol. Seismol., 1993, no. 3, pp. 23-45 [Volcanology and Seismology, 1994, vol. 15, no. 3, pp. 287-314, Gordon and Breach Science Publishers].

28. Fedotov, S.A., Zharinov, N.A., and Gorel'chik, V.I., Deformation and Earthquakes on Klyuchevskoi Volcano, a Model of Its Activity, Vulkanol. Seismol., 1988, no. 2, pp. $3-42$.

29. Firstov, P.P., Vulkanicheskie akusticheskie signaly diapazona 0.5-10 Gts $v$ atmosphere $i$ ikh svyaz's eksplozivnym protsessom (Volcanic Acoustic Signals in the Range 0.5-10 Hz in the Atmosphere and Their Relationship to the Explosive Process), Petropavlovsk-Kamchatskii: KamGPU, 2003. 
30. Firstov, P.P. and Storcheus, A.V., Acoustic Signals that Accompanied the March-June 1983 Eruption of Klyuchevskoi Volcano, Vulkanol. Seismol., 1987, no. 5, pp. 66-80.

31. Firstov, P.P. and Shirokov, V.A., Locating the Roots of the Klyuchevskoi Group Volcanoes from Seismological Data, in Vulkanizm i glubiny Zemli (Volcanism and the Earth's Interior), Moscow: Nauka, 1971, pp. 113-117.

32. Firstov, P.P., Adushkin, V.V., and Storcheus, A.V., Shock Air Waves Recorded in September 1975 during the Great Tolbachik Fissure Eruption, Dokl. AN SSSR, 1978, vol. 259, no. 5, pp. 1078-1081.

33. Khrenov, A.P., Makhanova, T.M., Bogatikov, O.A., and Plate, A.N., Results of Air-Borne Surveys of Kamchatka Volcanoes: The Klyuchevskoi Group of Volcanoes, Vulkanol. Seismol., 2002, no. 2, pp. 3-20.

34. Ertel', G, Jr., Putevoditel' Prandtlya po gidroaerodinamike (A Prandtl Handbook on the Dynamics of Liquids and Gases), Izhevsk: Institut Komp'yuternykh Issledovanii, 2007.

35. Bourseller, Ph. and Durieux, J., Des volcans et des hommes, 2001.

36. Carrigan, C.R., Schubert, G., and Eichelberger, J.C., Thermal and Dynamical Regimes of Single- and TwoPhase Magmatic Flow in Dikes, J. Geophys. Res., 1992, vol. 97, no. B12, pp. 17377-17392.

37. Chouet, B., Saccorotti, G., Martini, M., et al., Source and Path Effects in the Wave Fields of Tremor and Explosions at Stromboli Volcano, Italy, J. Geophys. Res., 1997, vol. 102, no. B7, pp. 15129-15150.

38. Delpha, S.La., Patane, G., Clocchiatti, R., et al., Activity of Mount Etna Preceding the February 1999 Fissure Eruption: Inferred Mechanism from Seismological and Geochemical Data, J. Volcanol. Geotherm. Res., 2001, vol. 105, pp. 121-139.

39. Jaupart, C., Magma Ascent at Shallow Levels, in Encyclopedia of Volcanoes, San Diego, Toronto: Academic Press, 2000, pp. 237-245.

40. Lees, J.M., Symons, N., Chubarova, O., et al., Tomographic Images of Kliuchevskoy Volcano P-Wave Velocity, in Volcanism and Subduction: The Kamchatka Region, Geophysical Monograph Series, 2007, vol. 172, pp. 293-302.

41. Macdonald, G.A., Volcanoes, New Jersey: Prentice-Hall Inc., Englewood Cliffs, 1972.

42. Manga, M., Waves of Bubbles in Magmatic Systems and Lavas, J. Geophys. Res., 1996, vol. 101, no. B8, pp. 1745717465 .
43. Manga, M. and Stone, H.A., Interactions between Bubbles in Magmas and Lavas: Effects of Deformation, J. Volcanol. Geotherm. Res., 1994, vol. 63, pp. 267-279.

44. Ozerov, A.Yu. and Konov, A.S., Regularities in the Dynamics of the Klyuchevskoy Volcano Eruption, in Proc. Kagoshima International Conf. Volcanoes, Japan, 1988, pp. 63-65.

45. Ozerov, A.Yu., The Evolution of High-Alumina Basalts of the Klyuchevskoy Volcano, Kamchatka, Russia, Based on Microprobe Analyses of Mineral Inclusions, J. Volcanol. Geotherm. Res., 2000, vol. 95, pp. 65-79.

46. Ozerov, A.Yu., Periodicities in the Dynamics of the Volcanic Eruptions in Kamchatka, in 32nd International Geological Congress, Florence, Italy, Abstracts, Part 1, 2004, p. 614.

47. Ozerov, A.Yu., Firstov, P.P., and Gavrilov, V.A., Periodicities in the Dynamics of Eruptions of Klyuchevskoy Volcano, Kamchatka, in Volcanism and Subduction: The Kamchatka Region, Geophysical Monograph Series, 2007, vol. 172, pp. 283-291.

48. Privitera, E., Sgroi, T., and Gresta, S., Statistical Analysis of Intermittent Volcanic Tremor Associated with the September 1989 Summit Explosive Eruptions at Mount Etna, Sicily, J. Volcanol. Geotherm. Res., 2003, vol. 120, pp. 235247.

49. Rittmann, A., Vulkane und ihre Taetigkeit, Stuttgart: Ferdinand Enke Verlag, 1960.

50. Sparks, R.S.J., The Dynamics of Bubble Formation and Growth in Magmas: A Review and Analysis, J. Volcanol. Geotherm. Res., 1978, vol. 3, pp. 1-37.

51. Utnasin, V.K., Abdurakhmanov, A.I., Anosov, G.I., et al., Types of Magma Foci of Island Arc Volcanoes and Their Study by the Method of Deep Seismic Sounding of Kamchatka, in Volcanoes and Tectonosphere, Tokai University Press, 1976, pp. 123-137.

52. Vergniolle, S. and Jaupart, C., Separated Two-Phase Flow and Basaltic Eruptions, J. Geophys. Res., 1986, vol. 91, pp. 12842-12860.

53. Vergniolle, S. and Jaupart, C., The Dynamics of Degassing at Kilauea Volcano, Hawaii, J. Geophys. Res., 1990, vol. 95, pp. 2793-2809.

54. Vergniolle, S. and Mangan, M., Hawaiian and Strombolian Eruptions, in Encyclopedia of Volcanoes, San Diego, Toronto: Academic Press, 2000, pp. 447-461.

55. Wallis Graham, B., One-Dimensional Two-Phase Flow, New York, Panama: McGraw-Hill Book Company, 1969. 